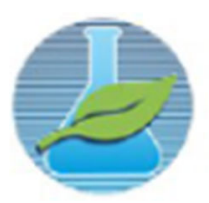

$\mathrm{JCEC} / \mathrm{REQ}^{2}$

Journal

ISSN: 2446-9416

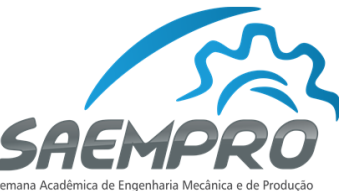

"EU, A INDÚSTRIA E O MUNDO"

08 a 11 de novembro de 2016 no campus Viçosa da UFV

Departamento de Engenharia de Produção e Mecânica - DEP

Universidade Federal de Viçosa - UFV

\title{
MATERIAIS E PROCESSOS UTILIZADOS NA FABRICAÇÃO DE TALHERES
}

\author{
Thomaz Santos Lisboa, Iago Carrara Roque e Andrei Morais Borém \\ Universidade Federal de Viçosa, Departamento de Engenharia de Produção e Mecânica \\ $\mathrm{Ph}$. Rolfs s/n - 36570-900 - Viçosa - MG \\ thomaz.lisboa@ufv.br, iago.roque@ufv.br, andrei.borem@ufv.br
}

\section{INTRODUÇÃ̃}

Apesar de serem utilizados quase que diariamente por várias pessoas ao redor do mundo, os talheres são instrumentos relativamente novos na sociedade. A popularização deles no Brasil se dá a partir do século XIX, sendo o uso das mãos utilizado para o consumo de alimentos até então (Lima, 1999).

Devido à funcionalidade vista diariamente destes utensílios, este trabalho tem como objetivo exemplificar nos tópicos seguintes os materiais utilizados para a produção de garfos, colheres e facas, e, principalmente, de seus respectivos processos de fabricação.

O presente trabalho tem como objetivo ilustrar os processos de fabricação (rota de fabricação) que podem ser empregados para fabricação de talheres na indústria, bem como os possíveis materiais utilizados neste produto.

\section{METODOLOGIA}

As informações fornecidas neste trabalho foram obtidas através de pesquisa na literatura atual, além de processos de fabricação revelados por empresas do setor.

\section{RESULTADOS}

\subsection{Materiais utilizados na fabricação}

A partir das propriedades comumente exigidas para talheres, tem-se que apesar de existirem opções como plástico e metais de alto valor (como a prata), os talheres são feitos em geral de aço inoxidável ou carbono. Ainda que possua um preço mais elevado em relação ao aço carbono, o aço inoxidável possuiu uma condutividade quase que 25\% mais baixa (Makeitfrom, 2016), além de apresentar uma maior durabilidade.

Assim, conclui-se a partir das características supracitadas que é mais vantajosa a produção com a utilização do aço inoxidável, portanto, os processos de fabricação mostrados no tópico seguinte empregam este material como matéria-prima.

\subsection{Fabricação de garfos e colheres a partir de um tarugo}

Para este tipo de fabricação, começa-se com um do processo de laminação do tarugo, obtendose uma chapa, que em seguida, sofre um corte exterior realizado em uma prensa para a criação do blank (que é diferente para garfos e colheres). Para a colher, entretanto, é necessário um processo extra de laminação na parte de cima do blank, fazendo com que a parte superior da mesma sofra uma expansão, deixando o aço mais fino. 
Após estes processos, ambos os utensílios passam por um processo de corte superior, um de forjamento e, o último processo de conformação, o dobramento. Em seguida, no acabamento, os talheres são polidos e ganham uma aparência mais brilhante, antes de serem encaminhados para a limpeza e inspeção. A Fig. 1 a seguir exemplifica o fluxograma do processo descrito:

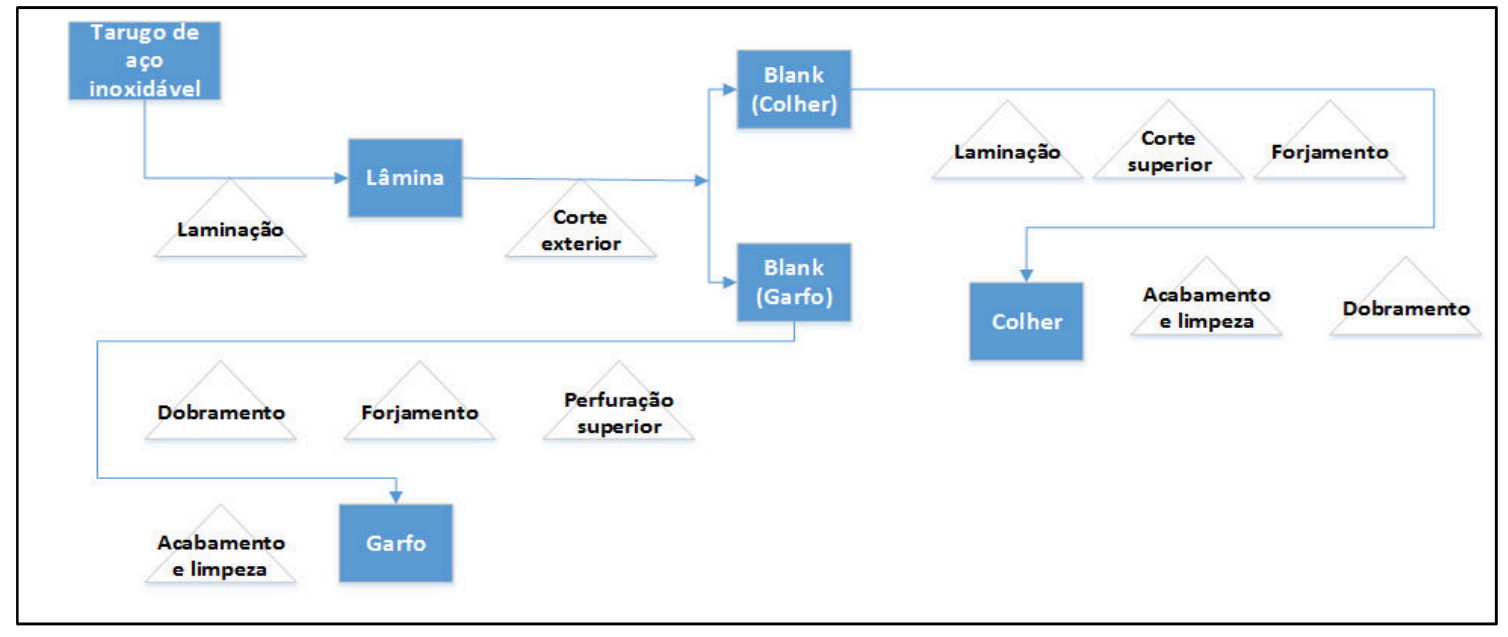

Figura 1 - Fluxograma da produção de garfos e colheres a partir de um tarugo.

\subsection{Fabricação de garfos e colheres através de um tubo cilíndrico}

Nesta opção, o processo começa com a extrusão do tubo de aço inoxidável, produzindo-se um fio longo. Em seguida, o fio é cortado em partes menores e, estas partes, são aquecidas e forjadas em matriz fechada, dando origem ao formato do cabo.

A partir deste ponto garfos e colheres se separam, uma vez que o primeiro passa pelo corte superior e dobramento, enquanto que a colher passa pelo processo de laminação, corte e dobramento.

Ambos os talheres deste processo também recebem acabamento e limpeza para serem enviados ao controle de qualidade, como informado no processo anterior. A Fig. 2 exemplifica o fluxograma do processo descrito:

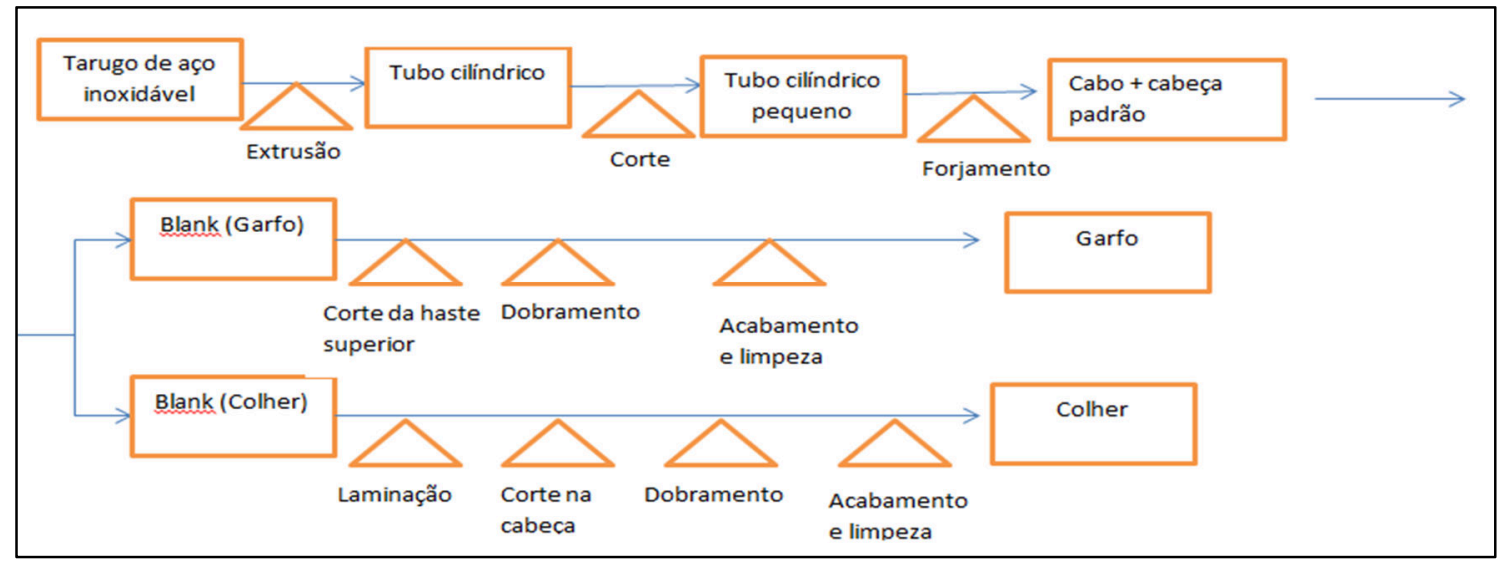

Figura 2 - Fluxograma da produção de garfos e colheres através da extrusão.

\subsection{Fabricação de facas}

Para a fabricação de facas, é necessário que o tarugo de aço sofra um processo de laminação, diminuindo a sua espessura e aumentando o seu comprimento. Em seguida, o formato da faca é moldado através do processo de estampagem e, após, faz-se a furação do resultado do último processo para que o utensílio receba as travas de sustentação dos cabos ao final da produção. 
Após a furação, as facas passam por um tratamento térmico, com o objetivo de aumentar a dureza do material, e, logo após o resfriamento, a retificação do material é realizada. Com isso, os cabos de sustentação podem ser adicionados e a produção das serras é feita através do processo de serramento. A Fig. 3 representa o fluxograma do processo:

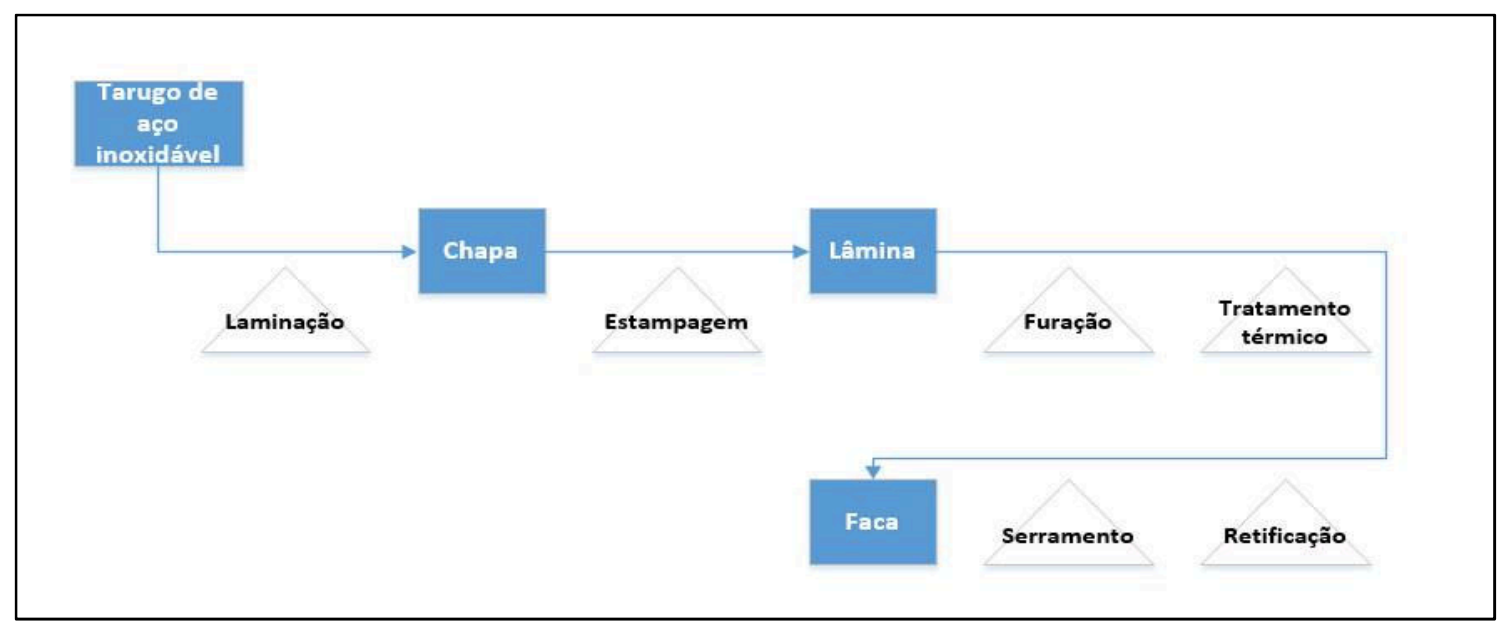

Figura 3 - Fluxograma da fabricação de facas.

\section{CONCLUSÕES}

Dentre as diferentes opções apresentadas, conclui-se que a tomada de decisão com relação ao tipo de processo de fabricação escolhido deve envolver o espaço disponível no chão de fábrica e preços das máquinas necessárias. Não existem opções corretas ou incorretas de processos, uma vez que cada material ou processo escolhido trará as suas vantagens ou desvantagens.

Além disso, pelos processos envolvidos, percebe-se que há uma grande automação da fabricação, permitindo-se que a produtividade seja elevada, e, por consequência, que os custos sejam reduzidos.

\section{REFERÊNCIAS}

DISCOVERY, 2015. "Fabricação de talheres de prata". Acesso em: 6 Jun. 2016. Disponível em: $<\mathrm{https}$ :/www.youtube.com/watch?v=LVLjHtV-WKM>

LIMA, 1999. "Tachos e panelas: Historiografia da alimentação brasileira." Recife: Ed. da autora, 1999. $2^{\text {a }}$ Ed. 310 p.

MAKEITFROM, 2016. "Material Properties". Acesso em: 5 Jun. 2016. Disponível em: $<$ http://www.makeitfrom.com/material-properties/AISI-420-1.4021-X20Cr13-S42000-StainlessSteel> 